\title{
The Normative Significance of Empirical Moral Psychology
}

\author{
- Tomasz Żuradzki -
}

\begin{abstract}
Many psychologists have tried to reveal the formation and processing of moral judgments by using a variety of empirical methods: behavioral data, tests of statistical significance, and brain imaging. Meanwhile, some scholars maintain that the new empirical findings of the ways we make moral judgments question the trustworthiness and authority of many intuitive ethical responses. The aim of this special issue is to encourage scholars to rethink how, if at all, it is possible to draw any normative conclusions by discovering the psychological processes underlying moral judgments.
\end{abstract} Keywords: moral psychology, empirical ethics, moral reasoning, metaethics, empathy, debunking arguments, foreign-language effect, the veil of ignorance, dual-process theory

Published online: 30 June 2020

In this special issue, we have brought together six theoretical papers that discuss whether it is possible to draw any normative conclusions from experimental research in moral psychology. Two of the papers critically discuss some recent empirical research on metaethics and normative ethics: Lance S. Bush and David Moss highlight serious problems with measuring folk metaethical views on objectivism and relativism, Steven McFarlane and Heather Cipolletti Perez criticize the well-known view that using one's non-native language reduces emotional arousal and increases the utilitarian response tendency in moral dilemmas. Two papers concern bioethics: Heidi Giebel argues that attributing increased moral status to fetal humans after seeing fetal ultrasound images may be rationally justified, and Michael Klenk proposes four ways in which moral psychology can play a significant role in bioethics, understood as a practically committed discipline. Finally, Norbert Paulo and Thomas Pölzler propose some new empirical research on impartiality thought experiments, and Wim De Neys, in his discussion note, discusses research that undermines any normative significance of dual-process theory.

The main motivation behind organizing this issue stems from recent work at the intersection of moral psychology and normative ethics that has tried to reveal the formation and processing of moral judgments, as well as identifying the emotional and cognitive barriers that distort normative judgments. Moreover, it has been argued in recent

Tomasz Żuradzki

Jagiellonian University

Institute of Philosophy \& Interdisciplinary Centre for Ethics

ul. Grodzka 52

31-044 Kraków, Poland

email: t.zuradzki@uj.edu.pl 
years that some cognitive biases and heuristics, or other psychological effects, influence the content of normative moral judgments. For example, some authors have argued that the status quo bias may strengthen hesitance about human enhancement (Bostrom \& Ord 2006; Hofmann 2020), that the similarity heuristic may distort some distributive trade-offs in healthcare (Voorhoeve, Stefánsson, Wallace 2019), and that the identifiability effect may lead to the inefficient use of scarce resources in healthcare (Źuradzki, 2019). These practical cases mirror more abstract discussions of whether new empirical findings undermine the reliability of some intuitive ethical responses or some traditional normative views (e.g., alleged experimental evidence against deontology, see: Greene 2014; cf. Heinzelmann 2018). Even more broadly, some have argued that new discoveries in experimental psychology cast new light on traditional metaethical questions, e.g., whether moral judgments are based on reason or on emotion, with some authors have argued that experimental moral psychology challenges traditional moral rationalism or moral realism (Nichols 2004; cf. May 2018). This new wave of empirical research on ethical issues has also revived discussions on debunking arguments in ethics (Sauer 2018).

Another important inspiration for this issue comes from behavioral research on risk perception, risk attitudes, ambiguity aversion, and decision making under risk or uncertainty in general. A good example is a recent discussion on the possible use of Prospect Theory (Kahneman 2011) in ethics: some scholars have argued that Prospect Theory is a better explanation of our intuitive responses to some moral dilemma than traditional ethical principles, like a distinction between doing and allowing (Horowitz 1998); others have reversed this order of explanation assuming that a distinction between doing and allowing is a genuine phenomenon that could explain some framing effects, e.g. the pattern of choices in the Asian Disease Problem (Dreisbach, Guevara 2017). Recently, it has also been speculated that some decision-makers (e.g., members of ethics committees) are prone to ambiguity aversion that affect the way they evaluate known uncertainties or risks (e.g., related to standard medical procedures), with the comparison of deep uncertainties (e.g., related to new advances in biomedicine) (Kimmelman 2012).

Finally, we encouraged submissions on the significance of empirical moral psychology for bioethics as it has been argued that the psychological effects documented by behavioral scientists influence the formation of normative judgments in bioethical contexts, e.g., the psychological underpinnings of the disagreement about the moral status of the human embryo. The biases and heuristics research program also has an impact on some of the main bioethical concepts, e.g., in the case of autonomy, it is debated how biases and heuristics research may change the understanding of this concept (Blumenthal-Barby 2016).

Selecting the papers for publication and the winners of the international essay prize competition was extremely difficult. The editors of Diametros ultimately decided to award three first prizes (6,000 PLN each) to Lance S. Bush and David Moss for the paper "Misunderstanding Metaethics: Difficulties Measuring Folk Objectivism and Relativism," to Steven McFarlane and Heather Cipolletti Perez for the paper "Some Challenges for Research on Emotion and Moral Judgment: The Moral Foreign-Language Effect as a Case Study," and to Norbert Paulo and Thomas Pölzler for the paper "X-Phi and Impartiality Thought Experiments: Investigating the Veil of Ignorance." 
In the first paper of this special issue of Diametros, Lance S. Bush and David Moss analyze recent research on the metaethical beliefs of ordinary people (Bush, Moss 2020). Although there is a considerable body of research suggesting that ordinary people are metaethical pluralists, the Authors argue that there are compelling reasons to believe that participants do not interpret questions as intended by researchers because they lack familiarity with the views they are being asked about due to their complex and difficult to grasp nature. They notice that some research about objectivism and relativism define these terms differently - either in terms of mind-independence or in terms of the scope of moral judgments. The paper also discusses (and describes an online experiment conducted on this issue) a paradigm used to evaluate folk metaethical beliefs, i.e., the disagreement paradigm that assumes that a judgment that it is possible for different people to be correct about two contradictory moral statements is interpreted as evidence of relativism.

Heidi Giebel evaluates the changes in moral judgment that sometimes take place when viewers of ultrasounds abandon the belief that fetal humans are due minimal moral consideration and instead adopt the judgment that fetal humans are morally comparable to fully developed humans (Giebel 2020). The problem is both theoretically interesting (on the epistemic role of photographic images as visual information see: Favaretto, Vears, Borry 2020) and practically relevant because many people argue that using ultrasound images may be used to manipulate women in an attempt to persuade them to continue with their pregnancies. Giebel analyzes three types of psychological explanation for the effect of ultrasound images of fetal humans on some viewers' judgments, arguing that the viewer's shift in beliefs is presumptively rational in each case.

Michael Klenk's paper discusses the "clouded relations" between bioethics and empirical moral psychology (Klenk 2020). The Author assumes that bioethics is not only practically oriented (as is the case with other parts of practical ethics) but also practically committed, that is, bioethicists aim to effect decisions in practice and devote significant efforts to making that happen. This "activist" aspect of bioethics makes moral psychology normatively significant for this discipline, even though it may be insignificant for normative ethics. Klenk argues that empirical moral psychology may help bioethicists to understand the actual or current state of a decision situation; the genealogy of our moral judgments; the effectiveness and realisability of bioethical decisions; and, last but not least, to revise at least some of our moral principles or decision guidelines.

In the next paper Steven McFarlane and Heather Cipolletti Perez analyze empirical research on the relation between using native language and being emotional on the example of the so-called moral foreign-language effect (MFLE). It assumes that individuals reasoning in a foreign language more often prefer a utilitarian option over a deontological one (McFarlane, Perez 2020). The Authors notice important methodological problems with measuring emotions, since experiments obviously do not test for "emotions" directly, but use different proxies and different methods (changes in skin conductance, neuroscientific evidence, behavioral response patterns, patterns in judgment responses, qualitative reports of the felt emotion, etc.). They conclude that using emotion as a proxy for deontological responses, and utilitarian responses as a proxy for reduced emotionality, is at least dubious, if not unjustified. 
Norbert Paulo and Thomas Pölzler notice an important gap in empirically-informed research on impartiality thought experiments, namely attempts to elicit intuitions that are unaffected by personal characteristics, e.g., age, gender, or race (Paulo, Pölzler 2020). They focus on a particularly influential example, the veil of ignorance, both in its original Rawlsian version (rVOI) and in a more generic form (iVOI), that is sometimes used in practical context (e.g., to defend quality-adjusted life years (QALYs) as a right method of measuring health). The Authors discuss possible experiments on the effectiveness of VOI, or the extent to which impartiality thought experiments fulfill the function for which they were created; and its robustness, that is, its (in)sensitivity to irrelevant factors. The paper concludes that this type of research - if conducted - could have at least one important implication: favoring a certain normative judgment behind the VOI (in comparison to the standard choice situation) provides stronger pro tanto evidence for accepting this judgment.

Finally, in a discussion note, Wim De Neys answers the main question of this issue in the negative, arguing that we cannot draw any normative conclusions by discovering the psychological processes underlying moral judgments (De Neys, 2020). He criticizes the part of the literature that associates biases with the operation of intuitive System 1, and that connects unbiased responses with the successful engagement of the deliberate System 2 (Greene 2013), noticing that the early dual-process theorists argued against this simplification, sometimes called a "normative fallacy" (Evans 2011). The Author observes that knowledge about the way (intuition vs. deliberation) people have arrived at a decision does not allow us to draw any conclusions about its normative correctness. Finally, the paper briefly reviews the recent literature in psychology that shows that utilitarian responses, contrary to what is very often assumed, do not typically result from System 2 processing (Baron, Gürçay 2017).

\section{Acknowledgments}

The editorial work on this issue of Diametros was partially (6 publishing sheets) supported by a grant from the Ministry of Science and Higher Education in Poland, the National Programme for the Development of Humanities, no. 0177/NPRH4/H3b/83/2016. This research received funding from the European Research Council (ERC) under the European Union's Horizon 2020 research and innovation programme (grant agreement No 805498) and benefited from a research stay at the Fondation Brocher (http://www. brocher.ch).

\section{References}

Baron J., Gürçay B. (2017), “A Meta-Analysis of Response-Time Tests of the Sequential Two-Systems Model of Moral Judgment," Memory \& Cognition 45 (4): 566-575.

Blumenthal-Barby J. (2016), "Biases and Heuristics in Decision Making and their Impact on Autonomy," The American Journal of Bioethics 16 (5): 5-15.

Bostrom N., Ord T. (2006), “The Reversal Test: Eliminating Status Quo Bias in Applied Ethics," Ethics 116 (4): 656-679.

Bush L.S., Moss D. (2020),"Misunderstanding Metaethics: Difficulties Measuring Folk Objectivism and Relativism," Diametros 17 (64): 6-21. 
De Neys W. (2020), “Morality, Normativity, and the Good System 2 Fallacy," Diametros 17 (64): 90-95.

Dreisbach S., Guevara D. (2017), “The Asian Disease Problem and the Ethical Implications of Prospect Theory," Nô̂s 53 (3): 613-638.

Evans J.S.B. (2011), “Dual-Process Theories of Reasoning: Contemporary Issues and Developmental Applications," Developmental Review 31 (2-3): 86-102.

Favaretto M., Vears D.F., Borry P. (2020), “On the Epistemic Status of Prenatal Ultrasound: Are Ultrasound Scans Photographic Pictures?," Journal of Medicine and Philosophy 45 (2): 231-250.

Giebel H. (2020), “Ultrasound Viewers' Attribution of Moral Status to Fetal Humans: A Case for Presumptive Rationality," Diametros 17 (64): 22-35.

Greene J.D. (2013), Moral Tribes: Emotion, Reason, and the Gap between Us and Them, Penguin Books, New York.

Greene J.D. (2014), “Beyond Point-and-Shoot Morality: Why Cognitive (Neuro) Science Matters for Ethics," Ethics 124 (4): 695-726.

Heinzelmann N. (2018), “Deontology Defended," Synthese 195 (12): 5197-5216.

Hofmann B. (2020), "Progress Bias versus Status Quo Bias in the Ethics of Emerging Science and Technology," Bioethics 34 (3): 252-263.

Horowitz T. (1998), "Philosophical Intuitions and Psychological Theory," Ethics 108 (2): 367-385.

Kahneman D. (2011), Thinking, Fast and Slow, Farrar, Straus, and Giroux, New York.

Kimmelman J. (2012), "Ethics, Ambiguity Aversion, and the Review of Complex Translational Clinical Trials," Bioethics 26 (5): 242-250.

Klenk M. (2020), “Charting Moral Psychology's Significance for Bioethics: Routes to Bioethical Progress, its Limits, and Lessons from Moral Philosophy," Diametros 17 (64): 36-55.

May J. (2018), Regard for Reason in the Moral Mind, Oxford University Press, Oxford.

McFarlane S., Cipolletti Perez, H. (2020), "Some Challenges for Research on Emotion and Moral Judgment: The Moral Foreign-Language Effect as a Case Study," Diametros 17 (64): 56-71.

Nichols S. (2004), Sentimental Rules: On the Natural Foundations of Moral Judgment, Oxford University Press, Oxford.

Paulo N., Pölzler T. (2020), "X-Phi and Impartiality Thought Experiments: Investigating the Veil of Ignorance," Diametros 17 (64): 72-89.

Sauer H. (2018), Debunking Arguments in Ethics, Cambridge University Press, Cambridge.

Voorhoeve A., Stefánsson A., Wallace B. (2019), "Similarity and the Trustworthiness of Distributive Judgements," Economics $\mathcal{E}$ Philosophy 35 (3): 537-561.

Żuradzki T. (2019), "The Normative Significance of Identifiability," Ethics and Information Technology 21 (4): 295-305. 